Original Research Paper

\title{
Optimization of Cellulase-Assisted Extraction of Total Flavonoids from Corn Bract and Evaluation of Antioxidant and Antibacterial Aactivities
}

\author{
${ }^{1}$ Yang Zhang, ${ }^{3}$ Jing Lu, ${ }^{1}$ Leijie Ben, ${ }^{1}$ Lixue Zheng, \\ ${ }^{1}$ Pengfei $\mathrm{Xu},{ }^{1}$ Yingang Jia, ${ }^{3} \mathrm{Zhenyu}$ Cheng and ${ }^{2} \mathrm{Zhaowei}$ Yan \\ ${ }^{I}$ School of Biology and Food Engineering, Changshu Institute of Technology, Changshu, Jiangsu 215500, China \\ ${ }^{2}$ Department of Pharmacy, The First Affiliated Hospital of Soochow University, Suzhou, Jiangsu 215006, China \\ ${ }^{3}$ School of Chemistry and Pharmaceutical Engineering, Jilin Institute of Chemical Technology, Jilin, Jilin 132022, China
}

Article history

Received: 20-01-2019

Revised: 01-03-2019

Accepted: 18-05-2019

Corresponding Authors:

Yang Zhang

School of Biology and Food

Engineering, Changshu Institute

of Technology, Changshu,

Jiangsu 215500, China

Email: zhangyang@cslg.edu.cn

Zhaowei Yan

Department of Pharmacy, The

First Affiliated Hospital of

Soochow University, Suzhou,

Jiangsu 215006, China

Email: yanzwsuzhou@163.com

\begin{abstract}
Corn bract is a corn-based agricultural waste material that distributed worldwide. In present work, response surface methodology was applied to optimize the cellulase-assisted extraction of Total Flavonoids from Corn Bract (TFCB), the in vitro antioxidant and antibacterial as well as the in vivo antioxidant activities of TFCB were investigated. Results showed that the optimal conditions for TFCB extraction were as follows: Amount of cellulase, $0.4 \%(\mathrm{w} / \mathrm{w})$; incubation time, $2 \mathrm{~h}$; liquid-to-solid ratio, 35: $1 \mathrm{~mL} / \mathrm{g}$; ethanol concentration, 71\% (v/v); TFCB yield was $1.284 \pm 0.01 \%$, which was $25.39 \%$ higher than that of heat reflux extraction. In addition, when compared with vitamin $\mathrm{C}$, TFCB showed weaker in vitro free radical-scavenging capacities, but stronger antioxidant activities in mice. Moreover, TFCB also exerted certain inhibitory effects against Gram-positive bacteria. This study will provide an evidence for the potential of comprehensive utilization of discarded corn bract.
\end{abstract}

Keywords: Corn Bract, Total Flavonoids, Cellulase-Assisted Extraction, Antioxidant Activity, Antibacterial Activity

\section{Introduction}

Corn (Zea mays L.), a member of the family Poaceae, is one of the most abundant crops cultivated worldwide (Barth, 2008; NWE, 2018). In addition to dietary property, some parts of corn have been utilized as therapeutic agents. Corn silk (Stigma maydis), the stigma and style of corn, is the most famous corn-based traditional medicine (Hasanudin et al., 2012). It consists of various bioactive constituents including flavonoids, tannins, steroids, alkaloids, polysaccharides, as well as vitamins (Peng et al., 2016) and possesses numerous pharmacological activities such as anti-diabetic, antioxidant, anti-tumor, anticoagulant, diuretic, etc (Zhao et al., 2017). Although the medicinal value of corn silk has been well studied and applied, regarding corn bract, the subtending leaf surrounding corn kernels (Fig. 1), there is little information on its active components, most of corn bracts are discarded as agricultural waste materials and open burning is a frequently-used disposal method (Luo et al., 2017).

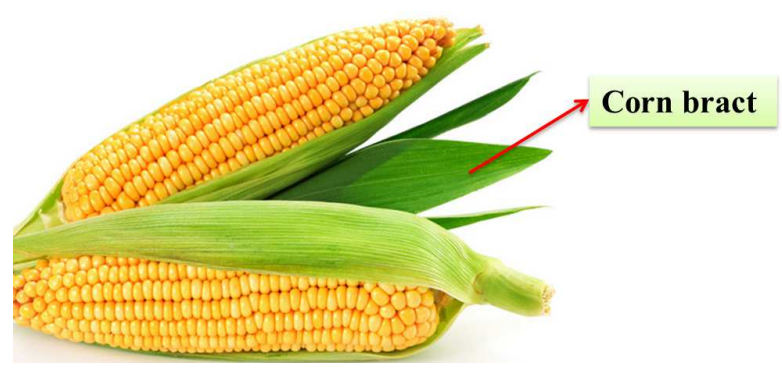

Fig. 1: The appearance of corn bract

Flavonoids are a kind of compounds widely distributed in plants as secondary metabolites (Zakaryan et al., 2017). An increasing number of studies have reported the extraction methods of flavonoids from different plant sources (Liu et al., 2016; Jing et al., 2016; Wang et al., 2017; Yang et al., 2017; Yu et al., 2017). Enzymeassisted extraction is established as an emerging technique to accelerate the release of bioactive components from plant materials, due to its advantages of high extraction yield, environmental compatibility, 
low energy requirement and simplified manipulation (Chen et al., 2011). Cellulase is one of the common used hydrolytic enzymes to hydrolyze and decompose the components of cell wall and enhance the release of intracellular constituents (Fu et al., 2008). Furthermore, cellulase has been proved to be efficient for the extraction of flavonoids from different kinds of plant materials including Illicium verum (Huang et al., 2016), Ampelopsis grossedentata (Gao et al., 2016), Larix gmelini (Wang et al., 2011) and Geranium sibiricum L. (Yang et al., 2010).

Reactive Oxygen Species (ROS)-induced oxidative stress is related to many kinds of diseases (Mao et al., 2017). Excess ROS can exert damaging effects on DNA, proteins and lipids, leading to cell aging and death (Lee and Wei, 2001; Martinez-Useros et al., 2017). It is therefore important to supplement exogenous antioxidants when facing oxidative stress, due to the fact that the levels or activities of endogenous antioxidants are usually lower than that required for the scavenging of free radicals (Szuroczki et al., 2016). Plant-derived flavonoids have multifold activities and the best described pharmacological activity of flavonoids is to act as potent natural-based antioxidant (Sarian et al., 2017). Moreover, a growing number of articles have demonstrated that antioxidant flavonoids always possess antimicrobial activities in vitro (Erasto et al., 2004; Liu et al., 2010; Hong et al., 2014; de Camargo et al., 2017).

In present investigation, with the aim of exploring the applicability of Cellulase-Assisted Extraction (CAE) for the preparation of Total Flavonoids from Corn Bract (TFCB), as well as the antioxidant and antibacterial potentials of TFCB. The Response Surface Methodology (RSM) coupled with Box-Behnken Design (BBD) was employed to optimize the process parameters of CAE for TFCB. Then, the in vitro antioxidant and antibacterial activities of TFCB were evaluated via different models and bacterial strains. Moreover, the in vivo antioxidant activities of TFCB were performed in an ethanol-induced oxidative stress mice model to further confirm its effects. The work described herein could be helpful for the comprehensive exploration and utilization of corn bract.

\section{Materials and Methods}

\section{Materials}

The dried corn bracts were harvested from the suburbs of Jilin City, China and authenticated by Prof. Guangshu Wang, School of Pharmaceutical Sciences, Jilin University (Jilin, Changchun, China). A voucher specimen (No. CB-007) was preserved in School of Biology and Food Engineering, Changshu Institute of Technology (Jiangsu, Changshu, China). Prior to experiment, corn bracts were grinded into powders and sieved to 60 -mesh.
Cellulase $(10000 \mathrm{U} / \mathrm{g})$ was obtained from Macklin Biochemical Co., Ltd. (Shanghai, China). Rutin was purchased from Winherb Medical Technology Co., Ltd. (Shanghai, China). Vitamin C (VC) was from Puripharm Co., Ltd. (Zhejiang, Huzhou, China). Chemicals used for the in vitro antioxidant evaluation including 1, 1-Diphenyl-2-Picrylhydrazyl (DPPH), Phenazine Methosulphate (PMS), 1, 10-phenanthroline, Nitroblue Tetrazolium (NBT) and Nicotinamide Adenine Dinucleotide (NADH), potassium ferricyanide $\left(\mathrm{K}_{3}\left[\mathrm{Fe}(\mathrm{CN})_{6}\right]\right)$, ferrous sulfate $\left(\mathrm{FeSO}_{4}\right)$, ferric chloride $\left(\mathrm{FeCl}_{3}\right)$ and hydrogen peroxide $\left(\mathrm{H}_{2} \mathrm{O}_{2}\right)$ were provided by Sigma Aldrich Chemical Co., Ltd (St. Louis, MO, USA). Other reagents and solvents with analytical grade such as aluminum nitrate (Al $\left.\left(\mathrm{NO}_{3}\right)_{3}\right)$, sodium nitrite $\left(\mathrm{NaNO}_{2}\right)$, methanol and ethanol, etc. were obtained from Sinopharm Chemical Reagent Co., Ltd. (Shanghai, China).

Reagent kits used for the in vivo antioxidant evaluation including Malonaldehyde (MDA), Total Superoxide Dismutase (T-SOD), Glutathione (GSH) and Protein Carbonyls (PCO) were provided by Jiancheng Biotechnology Co., Ltd. (Nanjing, Jiangsu, China).

\section{TFCB Extraction}

\section{Cellulase-Assisted Extraction (CAE)}

One gram of corn bract powders and $10 \mathrm{~mL}$ of Disodium Hydrogen Phosphate (DHP)-citric acid buffer solution $(\mathrm{pH}=5)$ were mixed together, then added certain cellulase $(0.1 \% \sim 0.6 \%$, respected to solid material) and incubated at $40^{\circ} \mathrm{C}$ for certain time $(0.5 \mathrm{~h} \sim$ $3 \mathrm{~h}$ ). After enzyme inactivation (boiling water bath, 5 min), added absolute ethanol and distilled water to adjust to certain liquid-to-solid ratio $(20: 1 \mathrm{~mL} / \mathrm{g} \sim 45: 1 \mathrm{~mL} / \mathrm{g}$ ) and certain ethanol concentration $(40 \% \sim 90 \%, \mathrm{v} / \mathrm{v})$, followed by extraction at $80^{\circ} \mathrm{C}$ for $2 \mathrm{~h}$. After cooling, the mixture was filtered and the total flavonoids in filtrate were determined by using an UV-visible spectrophotometer (722N, Jingke Scientific Instrument Co., Ltd., Shanghai, China). The TFCB extraction yield was expressed as follows:

$$
\text { Yield }(\%)=\frac{C \times V}{m} \times 100
$$

where, $C$ was the concentration of flavonoids $(\mathrm{mg} / \mathrm{mL})$, $V$ was the volume of filtrate $(\mathrm{mL})$ and $\mathrm{m}$ was the weight of corn bract powders (mg).

\section{Heat Reflux Extraction (HRE)}

One gram of corn bract powders and $10 \mathrm{~mL}$ of DHP-citric acid buffer solution $(\mathrm{pH}=5)$ were mixed together and incubated at $40^{\circ} \mathrm{C}$ for $2 \mathrm{~h}$, then added about $25 \mathrm{~mL}$ of absolute ethanol to adjust the ethanol 
concentration to $71 \%(\mathrm{v} / \mathrm{v})$, followed by extraction at $80 \square$ for $2 \mathrm{~h}$. After cooling, the mixture was filtered and the total flavonoids in filtrate were determined and the extraction yield was calculated.

\section{TFCB Content Determination}

TFCB content was determined according to the previously reported method (Khorasani et al., 2015) with some modifications. As much as $1 \mathrm{~mL}$ of diluted extract was mixed with $0.3 \mathrm{~mL}$ of $5 \% \mathrm{NaNO}_{2}$ solution, $0.3 \mathrm{~mL}$ of $10 \% \mathrm{Al}\left(\mathrm{NO}_{3}\right)_{3}$ solution and $4 \mathrm{~mL}$ of $30 \%(\mathrm{v} / \mathrm{v})$ methanol, then incubated and shaken for $6 \mathrm{~min}$, followed by the addition of $2 \mathrm{~mL}$ of $1 \mathrm{~mol} / \mathrm{L} \mathrm{NaOH}$ solution. Then, the mixture was diluted to $10 \mathrm{~mL}$ with $30 \%(\mathrm{v} / \mathrm{v})$ methanol and the absorbance was measured at $510 \mathrm{~nm}$, which was put into the regression equation to calculate TFCB content. The regression equation using rutin as standard substance was expressed as follows:

$A=36.557 C-0.0002\left(R^{2}=0.9998\right)$

where, $A$ was the absorbance, $C$ was the concentration of flavonoids $(\mathrm{mg} / \mathrm{mL})$ and the linear range was from 0.004 to $0.02 \mathrm{mg} / \mathrm{mL}$.

\section{Experimental Design of Response Surface Optimization}

In order to assess the effect of each factor on TFCB extraction yield, single-factor experiments were conducted to analyze the influences of the four independent variables including amount of cellulase $(0.1 \% \sim 0.6 \%$, w/w), incubation time $(0.5 \mathrm{~h} \sim 3 \mathrm{~h})$, liquid-to-solid ratio (20: 1 $\mathrm{mL} / \mathrm{g} \sim 45: 1 \mathrm{~mL} / \mathrm{g})$ and ethanol concentration $(40 \% \sim$ $90 \%, \mathrm{v} / \mathrm{v})$. Then, the CAE optimization of TFCB was further performed by using RSM (Zhang et al., 2013). A four-variable and three-level BBD comprising 29 runs was applied at the center point (Table 1).

Regression analysis was used for the experimental data and fitted to the following second-order polynomial equation:

$$
Y=\beta_{O}+\sum_{i=1}^{4} \beta_{i} X_{i}+\sum_{i=1}^{4} \beta_{i i} X_{i}^{2}+\sum_{i=1}^{3} \sum_{j=i+1}^{4} \beta_{i j} X_{i} Y_{j}
$$

where, $Y$ represents the response function. $\beta_{0}$ is an intercept. $\beta_{i}, \beta_{i i}$ and $\beta_{i j}$ are coefficients of the linear, quadratic and interactive terms, respectively. $X_{i}$ and $X_{j}$ represent the coded independent variables.

The experimental design, results analysis and responses prediction were carried out by using Design-Expert software 8.0.6.1 (Stat-Ease, Minneapolis, MN, USA).
Table 1: The code and level of factors selected for the trials Level

\begin{tabular}{|c|c|c|c|}
\hline \multirow[b]{2}{*}{ Independent variable } & \\
\hline & -1 & 0 & 1 \\
\hline Amount of cellulase $\left(\mathrm{w} / \mathrm{w}, \%, \mathrm{X}_{1}\right)$ & 0.3 & 0.4 & 0.5 \\
\hline Incubation time $\left(\mathrm{h}, \mathrm{X}_{2}\right)$ & 1.5 & 2.0 & 2.5 \\
\hline Liquid-to-solid ratio $\left(\mathrm{mL} / \mathrm{g}, \mathrm{X}_{3}\right)$ & $30: 1$ & 35: 1 & 40: 1 \\
\hline Ethanol concentration $\left(\mathrm{v} / \mathrm{v}, \%, \mathrm{X}_{4}\right)$ & 60 & 70 & 80 \\
\hline
\end{tabular}

\section{In vitro Antioxidant Activity of TFCB}

\section{DPPH Radical-Scavenging Capacity}

The DPPH radical-scavenging assay of TFCB was conducted according to the previously reported method (Liu et al., 2009) with some modifications. As much as 2 $\mathrm{mL}$ of TFCB solution with various concentrations (10 $\mu \mathrm{g} / \mathrm{mL} \sim 60 \mu \mathrm{g} / \mathrm{mL}$ ) was mixed with $2 \mathrm{~mL}$ of $0.1 \mathrm{mmol} / \mathrm{L}$ DPPH solution (dissolved in ethanol) and incubated at room temperature for $30 \mathrm{~min}$, followed by measuring the absorbance at $517 \mathrm{~nm}\left(A_{s}\right)$. The reaction system without DPPH was employed as normal control $\left(A_{c}\right)$, while, system without TFCB was used as blank solution $\left(A_{0}\right)$. VC solution at different concentrations $(4 \mu \mathrm{g} / \mathrm{mL} \sim 20 \mu \mathrm{g} / \mathrm{mL})$ was used as positive control. The capacity to scavenge DPPH radical was calculated by using the following equation:

$$
\begin{aligned}
& \text { DPPH radical }- \text { scavenging rate }(\%) \\
& =\left(A_{s}-A_{c}\right) \times 100 / A_{0}
\end{aligned}
$$

\section{Hydroxyl Radical-Scavenging Capacity}

Hydroxyl radical-scavenging capacity of TFCB was investigated based on the method reported by $\mathrm{Ke}$ and Chen (2016) with some modifications. As much as $2 \mathrm{~mL}$ of TFCB solution with different concentrations (100 $\mu \mathrm{g} / \mathrm{mL} \sim 600 \mu \mathrm{g} / \mathrm{mL}$ ) was mixed with $1 \mathrm{~mL}$ of 0.75 $\mathrm{mmol} / \mathrm{L} \mathrm{1,} \mathrm{10-phenanthroline} \mathrm{(dissolved} \mathrm{in} \mathrm{phosphate}$ buffer saline (PBS), $\mathrm{pH} 7.4$ ), then added $1 \mathrm{~mL}$ of 0.75 $\mathrm{mmol} / \mathrm{L} \mathrm{FeSO}_{4}$ as well as equal volume of $0.12 \%(\mathrm{v} / \mathrm{v})$ $\mathrm{H}_{2} \mathrm{O}_{2}$ solution, followed by reacting at $37^{\circ} \mathrm{C}$ for $60 \mathrm{~min}$. The absorbance $\left(A_{s}\right)$ was measured at $536 \mathrm{~nm}$. The reaction system without $\mathrm{H}_{2} \mathrm{O}_{2}$ was used as normal control $\left(A_{c}\right)$ and the system without TFCB was used as blank control $\left(A_{0}\right)$. VC solution in the concentration ranging from $25 \mu \mathrm{g} / \mathrm{mL}$ to $150 \mu \mathrm{g} / \mathrm{mL}$ was used as positive control. The capacity to scavenge hydroxyl radical was calculated as the following formula:

$$
\begin{aligned}
& \text { Hydroxyl radical - scavenging rate }(\%) \\
& =\left(A_{s}-A_{0}\right) \times 100 /\left(A_{c}-A_{0}\right)
\end{aligned}
$$

\section{Superoxide Anion Radical-Scavenging Capacity}

Superoxide anion radical-scavenging capacity of TFCB was evaluated by using the method reported by 
El-Beshbishy et al. (2009) with some modifications. As much as $1 \mathrm{~mL}$ of TFCB solution with varying concentrations $(10 \mu \mathrm{g} / \mathrm{mL} \sim 60 \mu \mathrm{g} / \mathrm{mL})$ was mixed with $3 \mathrm{~mL}$ of $16 \mathrm{mmol} / \mathrm{L}$ Tris- $\mathrm{HCl}$ buffer $(\mathrm{pH} \mathrm{8.0)}$ containing $0.5 \mathrm{~mL}$ of $0.47 \mathrm{mmol} / \mathrm{L} \mathrm{NADH}$ and $0.5 \mathrm{~mL}$ of 0.3 $\mathrm{mmol} / \mathrm{L} \mathrm{NBT}$, followed by adding $0.5 \mathrm{~mL}$ of 0.06 $\mathrm{mmol} / \mathrm{L}$ PMS to start the reaction. After incubation at room temperature for $5 \mathrm{~min}$, the absorbance was measured at $560 \mathrm{~nm}\left(A_{s}\right)$. The mixture in absence of TFCB was used as blank control $\left(A_{0}\right)$. VC solution with different concentrations $(5 \mu \mathrm{g} / \mathrm{mL} \sim 30 \mu \mathrm{g} / \mathrm{mL})$ was used as positive control. The capacity to scavenge superoxide anion radical was calculated by the following equation:

Superoxide anion - scavenging rate $(\%)$

$=\left(A_{0}-A_{s}\right) \times 100 / A_{0}$

\section{Reducing Power}

Reducing power of TFCB to ferric iron was determined based on the method reported by Vaquero et al. (2010) with some modifications. As much as $1 \mathrm{~mL}$ of TFCB solution with different concentrations $(3 \mu \mathrm{g} / \mathrm{mL} \sim 18 \mu \mathrm{g} / \mathrm{mL})$ was mixed with $2.5 \mathrm{~mL}$ of $0.2 \mathrm{~mol} / \mathrm{L}$ phosphate buffer $(\mathrm{pH} 6.6)$ and 2.5 $\mathrm{mL}$ of $1 \%(\mathrm{w} / \mathrm{v}) \mathrm{K}_{3}\left[\mathrm{Fe}(\mathrm{CN})_{6}\right]$ solution, followed by incubating at $50^{\circ} \mathrm{C}$ for $20 \mathrm{~min}$. Then $2.5 \mathrm{~mL}$ of $10 \%$ ( $\mathrm{v} / \mathrm{v})$ trichloroacetic acid was added, after shaking, the mixture was centrifuged at $3000 \mathrm{rpm}$ for $10 \mathrm{~min}$. As much as $5 \mathrm{~mL}$ of the supernatant was mixed with $4 \mathrm{~mL}$ of distilled water and $1 \mathrm{~mL}$ of $0.1 \%(\mathrm{w} / \mathrm{v}) \mathrm{FeCl}_{3}$ solution for $10 \mathrm{~min}$, then the absorbance at $700 \mathrm{~nm}$ was read. VC solution in the concentration range $5 \mu \mathrm{g} / \mathrm{mL}$ to $30 \mu \mathrm{g} / \mathrm{mL}$ was used as positive control.

\section{In vitro Antibacterial Activity of TFCB}

\section{Bacteria and Culture Condition}

The test bacteria including three Gram positive ones (Staphylococcus aureus ATCC 49775, Bacillus pumilus ATCC 14884 and Bacillus subtilis ATCC 21332) and two Gram negative ones (Escherichia coli ATCC 33456 and Salmonella typhimurium ATCC 14028) were provided by ATCC Global Bioresource Center (Manassas, VA, USA) and stored at $-80^{\circ} \mathrm{C}$ in $30 \%$ (v/v) glycerol media.

Prior to experiment, all the strains were subcultured in Luria-Bertani (LB) broth (Sangon Biotech Co., Ltd., Shanghai, China) for $24 \mathrm{~h}$ at $37^{\circ} \mathrm{C}$. The activated bacteria were diluted with sterile water to obtain the suspension of bacterial strain at concentration of $1.0 \times 10^{8} \mathrm{cfu} / \mathrm{mL}$.

\section{Minimum Inhibitory Concentration (MIC) Determination}

The minimum inhibitory concentration (MIC) of TFCB was determined by serial dilution microplate method (Bisi-Johnson et al., 2017). The tested concentrations of TFCB were from $0.5 \mu \mathrm{g} / \mathrm{mL}$ to 50 $\mu \mathrm{g} / \mathrm{mL}$. MIC values were defined as the lowest concentration of TFCB inhibiting bacterial growth after being incubated at $37^{\circ} \mathrm{C}$ for $18 \mathrm{~h}$.

\section{Animals and in vivo Antioxidant Activity of TFCB}

\section{Experimental Animals}

Male ICR mice with SPF grade (aged 4 weeks, weighed $18 \mathrm{~g} \sim 22 \mathrm{~g}$ ) were obtained from JOINN Laboratories (Suzhou) (Approval No. SCXK (Su) 20130003, Jiangsu, Suzhou, China). Mice were allowed free access to food and water and reared in polypropylene cages. The feeding conditions were as follows: temperature: $18^{\circ} \mathrm{C} \sim 22^{\circ} \mathrm{C}$; relative humidity: $50 \% \sim$ $60 \%$; light/dark regime: $12 \mathrm{~h}$. Animal experiments were carried out according to the National Institutes of Health Guide for the Care and Use of Laboratory Animals (NIH Publications No. 8023, revised 1978) and approved by the Animal Care and Welfare Committee of the First Affiliated Hospital of Soochow University (Approval No. 2018-092).

\section{In vivo Antioxidant Activity of TFCB}

Sixty mice were randomly divided into six groups ( $\mathrm{n}=10$ in each group) as follows: Normal Control (NC), Positive Control (PC), Model Control (MC) as well as three TFCB-treated groups, which were administered with TFCB in different doses of 50, 100 and $200 \mathrm{mg} / \mathrm{kg}$ once a day for 30 consecutive days, respectively. Mice in $\mathrm{PC}$ were dosed with $\mathrm{VC}$ in a dose of $200 \mathrm{mg} / \mathrm{kg}$, while, mice in $\mathrm{NC}$ and MC groups were treated with distilled water. On the last day, all the animals except for ones in NC were orally treated with $50 \%(\mathrm{v} / \mathrm{v})$ ethanol solution in a dose of $12 \mathrm{~mL} / \mathrm{kg}$ to induce oxidative stress, followed by being anesthetized with pentobarbital sodium after $6 \mathrm{~h}$. Then blood samples were harvested from orbit to obtain serum for the quantification of MDA and T-SOD. After that, animals were euthanized by using carbon dioxide, the livers were immediately dissected, washed and homogenized for the determination of GSH and PCO. Levels of MDA, T-SOD, GSH and PCO were determined based the methods provided in the kits instructions (Jiancheng Biotechnology Co., Ltd, Nanjing, Jiangsu, China) (Peng et al., 2015).

\section{Statistical Analysis}

Data was expressed as means \pm or + SD (standard deviation). Statistical analysis was conducted by using SPSS19.0 software (SPSS Inc., Chicago, USA). The $t$ test and one-way Analysis of Variance (ANOVA) were used to evaluate the significance of distances between two means or multiple means, respectively. 


\section{Results and Discussion}

Optimization of CAE Parameters for TFCB Extraction

Effects of Amount of Cellulase, Incubation Time, Liquid-to-Solid Ratio and Ethanol Concentration on the Extraction Yield of TFCB

As shown in Fig. 2a, in the range of $0.1 \% \sim 0.4 \%$ $(\mathrm{w} / \mathrm{w})$ cellulase, TFCB yield increased with the increase of cellulase amount, which reached the highest level at cellulase amount of $0.4 \%$. Then, with the increase of cellulase, TFCB yield decreased. These results indicated that cellulase could enhance the TFCB release by decomposing the components of cell wall, but when enzyme is fully saturated with substrate, the TFCB release could be reduced due to the fact that excess cellulase might make the solution viscous, which is not conducive to the enzymatic hydrolysis (Huang et al., 2016).

To examine the effects of incubation time for enzymatic reaction on TFCB yield, a range of $0.5 \mathrm{~h} \sim 3 \mathrm{~h}$ incubation time was selected (Fig. 2b). Results showed that TFCB yield achieved maximum value at incubation time of $2 \mathrm{~h}$, while, after $2 \mathrm{~h}$, prolonged incubation time caused the decrease of TFCB yield, suggesting that cellulase could completely decompose cell wall of corn bract and release the maximum amount of total flavonoids within a $2 \mathrm{~h}$-incubation period.

As shown in Fig. 2c, TFCB yield was remarkably raised with the increase of solvent amount spanning from $20: 1 \mathrm{~mL} / \mathrm{g} \sim 25: 1 \mathrm{~mL} / \mathrm{g}$, then was slightly raised with the solvent ranging from $25: 1 \mathrm{~mL} / \mathrm{g} \sim 35$ : $1 \mathrm{~mL} / \mathrm{g}$ and reached the highest level at the liquid-tosolid ratio of $35: 1 \mathrm{~mL} / \mathrm{g}$, after which it was reduced. The decreased TFCB yield may be due to the fact that larger volume of solvent could result in excessive swelling of corn bract powders and absorbing TFCB (Xiao et al., 2008).

The effects of ethanol concentration on TFCB yield were investigated from $40 \%$ to $90 \%(\mathrm{v} / \mathrm{v})$. It was seen in Fig. $2 \mathrm{~d}$ that ethanol concentration showed great impacts on TFCB yield and the ethanol concentration of $70 \%$ led to a highest extraction yield. Too low or too high ethanol concentrations are not conducive to the optimum extraction of flavonoids, which depend on the polarity of ethanol solution as well as the types of flavonoids present in corn bract (Huang et al., 2016).
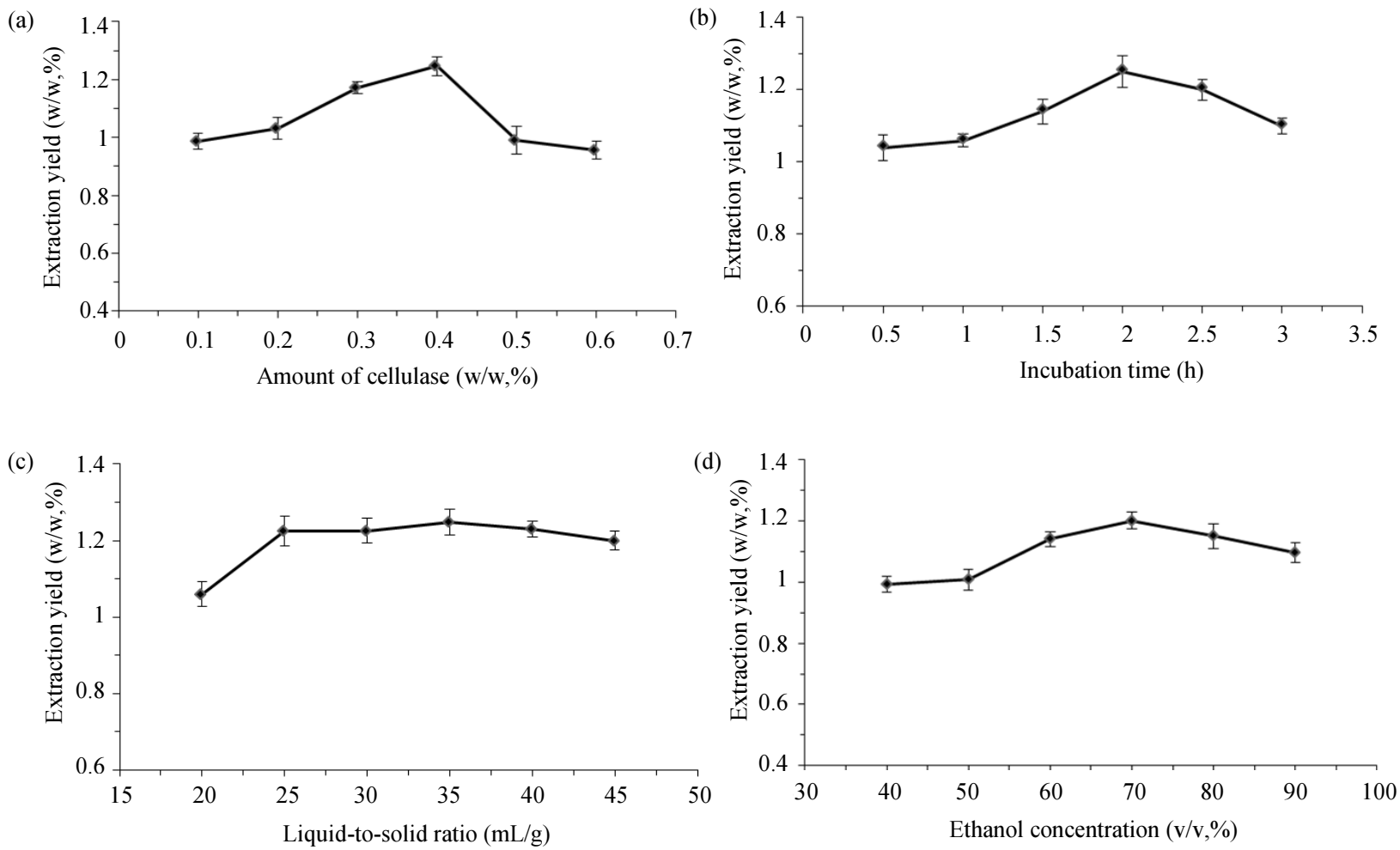

Fig. 2: Effects of (a) amount of cellulase (b) incubation time (c) liquid-to-solid ratio and (d) ethanol concentration on the extraction yield of TFCB. Data was expressed as the means $\pm \mathrm{SD}(\mathrm{n}=3)$ 
Table 2: Box-Behnken design and observed responses Independent variable

\begin{tabular}{llllll} 
Run & $\mathrm{X}_{1}$ & $\mathrm{X}_{2}$ & $\mathrm{X}_{3}$ & $\mathrm{X}_{4}$ & $\mathrm{Y}$ \\
\hline 1 & 0 & 1 & 1 & 0 & 1.098 \\
2 & 1 & 0 & -1 & 0 & 0.996 \\
3 & -1 & 0 & 0 & 1 & 1.120 \\
4 & 1 & 1 & 0 & 0 & 1.012 \\
5 & 0 & 0 & 1 & -1 & 1.064 \\
6 & 0 & 0 & 0 & 0 & 1.273 \\
7 & 1 & 0 & 0 & 1 & 1.132 \\
8 & 0 & 0 & 0 & 0 & 1.286 \\
9 & 0 & 1 & 0 & 1 & 1.124 \\
10 & 0 & 0 & -1 & 1 & 1.021 \\
11 & 0 & -1 & -1 & 0 & 1.021 \\
12 & -1 & 0 & 0 & -1 & 0.986 \\
13 & 0 & -1 & 0 & 1 & 0.998 \\
14 & 0 & -1 & 1 & 0 & 1.051 \\
15 & 0 & 1 & 0 & -1 & 1.028 \\
16 & -1 & 0 & 1 & 0 & 1.008 \\
17 & 0 & -1 & 0 & -1 & 1.025 \\
18 & 0 & 0 & 0 & 0 & 1.298 \\
19 & 1 & -1 & 0 & 0 & 0.998 \\
20 & 0 & 0 & 0 & 0 & 1.330 \\
21 & -1 & -1 & 0 & 0 & 1.023 \\
22 & -1 & 1 & 0 & 0 & 0.976 \\
23 & 1 & 0 & 1 & 0 & 1.099 \\
24 & 1 & 0 & 0 & -1 & 1.019 \\
25 & -1 & 0 & -1 & 0 & 1.098 \\
26 & 0 & 1 & -1 & 0 & 1.106 \\
27 & 0 & 0 & -1 & -1 & 0.989 \\
28 & 0 & 0 & 0 & 0 & 1.332 \\
29 & 0 & 0 & 1 & 1 & 1.019 \\
\hline & & & & &
\end{tabular}

\section{Model Fitting and Statistical Analysis}

According to the principles of $\mathrm{BBD}$, the values of independent variables including amount of cellulase (w/w, \%), incubation time (h), liquid-to-solid ratio $(\mathrm{mL} / \mathrm{g})$ and ethanol concentration $(\mathrm{v} / \mathrm{v}, \%)$ were selected based on the results of single-factor experiments and applied to the RSM test using TFCB extraction yield (w/w, \%) as the response variable (Table 2). 29 different experimental combinations and response values were described in Table 2 and the TFCB extraction yield ranged from $0.976 \% \sim 1.332 \%(w / w)$, which could be described by a response surface quadratic model via multiple regression analysis. The response variable $\mathrm{Y}$ (TFCB extraction yield) could be related by the following second-order polynomial equation:

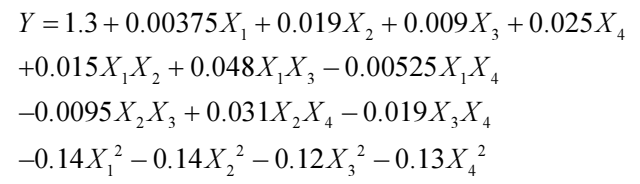

where, $Y$ means TFCB extraction yield (w/w, \%) and $X_{1}$, $X_{2}, X_{3}$ and $X_{4}$ represent amount of cellulase (w/w, \%), incubation time $(h)$, liquid-to-solid ratio $(\mathrm{mL} / \mathrm{g})$, ethanol concentration $(\mathrm{v} / \mathrm{v}, \%)$, respectively.

Table 3 exhibited one-way Analysis of Variance (ANOVA) for the fitted equation. The $F$-value was calculated to be 10.85 and the $P$-value was less than 0.0001 , implying that the model obtained was highly significant. The determination coefficient value of model $\left(\mathrm{R}^{2}\right)$ was 0.9156 , indicating that approximately $91.56 \%$ of the response variability could be explained by the model. In addition, the $F$-value for lack of fit was 3.76 and the $P$-value was 0.1070 , greater than 0.05 , implying a statistical non-significance thereby confirming the validity of the model. In this model, the linear parameters $\mathrm{X}_{1}, \mathrm{X}_{2}$, $\mathrm{X}_{3}$ and $\mathrm{X}_{4}$ were not significant $(p>0.05)$. The quadratic terms $\mathrm{X}_{1}^{2}, \mathrm{X}_{2}^{2}, \mathrm{X}_{3}{ }^{2}$ and $\mathrm{X}_{4}{ }^{2}$ were highly significant $(p<0.01)$. The interaction parameters $\mathrm{X}_{1} \mathrm{X}_{2}, \mathrm{X}_{1} \mathrm{X}_{3}, \mathrm{X}_{1} \mathrm{X}_{4}$, $\mathrm{X}_{2} \mathrm{X}_{3}, \mathrm{X}_{2} \mathrm{X}_{4}$ and $\mathrm{X}_{3} \mathrm{X}_{4}$ were not significant $(p>0.05)$, which indicated that interactions of any two of the four variables were not significant. Response surfaces were plotted by using Design-Expert software (version 8.0.6.1) to visualize interactions between the variables. The relationships between TFCB extraction yield and any two independent variables (the other variables were set to "0" level) were shown in Fig. 3.

\section{Verification of Predictive Model}

The optimal conditions of CAE for TFCB obtained by using RSM were as follows: Amount of cellulase, $0.40 \%$ (w/w); incubation time, $2.04 \mathrm{~h}$; liquid-to-solid ratio, 35.15: $1 \mathrm{~mL} / \mathrm{g}$; ethanol concentration, $71.05 \%(\mathrm{v} / \mathrm{v})$; the predicted extraction yield of TFCB was $1.306 \%(\mathrm{w} / \mathrm{w})$. Considering the convenience of practical operation, the optimal conditions were modified as follows: amount of cellulase, $0.4 \%(\mathrm{w} / \mathrm{w})$; incubation time, $2 \mathrm{~h}$; liquid-to-solid ratio, 35: $1 \mathrm{~mL} / \mathrm{g}$; ethanol concentration, $71 \%(\mathrm{v} / \mathrm{v})$, under these conditions, the actual extraction yield was $1.284 \pm 0.01 \%(w / w)(n=3)$, which were also higher than any single factor experiments.

\section{The Influence of Cellulase on TFCB Release}

In this study, TFCB extraction by CAE was compared with that of Heat Reflux Extraction (HRE). As shown in Table 4 , the yield of TFCB obtained by CAE was significantly $(p<0.01)$ higher than that obtained by HRE, suggesting that cellulase plays an important role on the release of TFCB from cell.

\section{In vitro Antioxidant Activity of TFCB}

Figure $4 \mathrm{a} \sim 4 \mathrm{c}$ showed the in vitro antioxidant activities of TFCB against 1, 1-diphenyl-2-picrylhydrazyl (DPPH), hydroxyl and superoxide anion radicals, Figure $4 \mathrm{~d}$ exhibited the reducing power to ferric ion and the half inhibitory concentration $\left(\mathrm{IC}_{50}\right)$ values were depicted in Table 5. The DPPH radical-scavenging capacities of TFCB were elevated with the increase of concentration 
ranging from $10 \mu \mathrm{g} / \mathrm{mL}$ to $60 \mu \mathrm{g} / \mathrm{mL}$, the highest scavenging rate was $80.54 \pm 1.06 \%$, the $\mathrm{IC}_{50}$ value was $34.02 \pm 0.52 \mu \mathrm{g} / \mathrm{mL}$, which was significantly $(p<0.01)$ higher than that of vitamin $\mathrm{C}(\mathrm{VC})$ with a $\mathrm{IC}_{50}$ value of $5.82 \pm 0.07 \mu \mathrm{g} / \mathrm{mL}$ (Fig. 4a). As shown in Fig. 4b, in the concentration range $100 \mu \mathrm{g} / \mathrm{mL}$ to $600 \mu \mathrm{g} / \mathrm{mL}$, TFCB exerted scavenging capacities against hydroxyl radical, which increased with the increase of concentration, the highest scavenging rate was $81.52 \pm 2.42 \%$, but inferior to VC, the $\mathrm{IC}_{50}$ value was still significantly $(p<0.01)$ higher than that of VC $(200.55 \pm 6.43 \mu \mathrm{g} / \mathrm{mL} v s .47 .36 \pm 1.20$ $\mu \mathrm{g} / \mathrm{mL}$ ). As for the superoxide anion radical (Fig. 4c), in the concentration range $10 \mu \mathrm{g} / \mathrm{mL}$ to $60 \mu \mathrm{g} / \mathrm{mL}$, the free radical scavenging capacities of TFCB were raised with the elevation of concentration, the highest scavenging rate was $92.38 \pm 2.29 \%$ in the concentration of $60 \mu \mathrm{g} / \mathrm{mL}$, the $\mathrm{IC}_{50}$ value was $17.18 \pm 0.97 \mu \mathrm{g} / \mathrm{mL}$, which was a little higher than that of $\mathrm{VC}(15.78 \pm 0.058 \mu \mathrm{g} / \mathrm{mL})$, but no significant differences $(p>0.05)$ were found. The reducing powers of TFCB to ferric ion were shown in Fig. $4 \mathrm{~d}$, in the concentration range $3 \mu \mathrm{g} / \mathrm{mL}$ to $18 \mu \mathrm{g} / \mathrm{mL}$, the absorbance (A) of TFCB at $700 \mathrm{~nm}$ was gradually raised with the elevation of concentration, when $A_{700 \mathrm{~nm}}$ was 0.2 , the concentration of TFCB was $10.39 \pm 0.21$ $\mu \mathrm{g} / \mathrm{mL}$, while, the concentration of $\mathrm{VC}$ was $7.87 \pm 0.017$ $\mu \mathrm{g} / \mathrm{mL}$, significant differences $(p<0.01)$ were observed. These results indicated that TFCB exerts certain scavenging capacities against DPPH, hydroxyl and superoxide anion radicals, as well as reducing powers to ferric ion in different concentration ranges. According to the $\mathrm{IC}_{50}$ values presented in Table 5 , in addition to superoxide anion radical, TFCB showed weaker scavenging or reducing capacities against DPPH, hydroxyl and ferric ion compared with VC.

Table 3: Box-Behnken design and observed responses

\begin{tabular}{|c|c|c|c|c|c|c|}
\hline Source $^{a}$ & Sum of squares & $\mathrm{DF}^{\mathrm{b}}$ & Mean square & $F$-value & $P$-value & Significance $^{\mathrm{c}}$ \\
\hline Model & 0.31 & 14 & 0.022 & 10.85 & $<0.0001$ & \\
\hline $\mathrm{X}_{1}$ & $1.688 \times 10^{-4}$ & 1 & $1.688 \times 10^{-4}$ & 0.082 & 0.7791 & n.s. \\
\hline $\mathrm{X}_{2}$ & $4.332 \times 10^{-3}$ & 1 & $4.332 \times 10^{-3}$ & 2.10 & 0.1694 & n.s. \\
\hline $\mathrm{X}_{3}$ & $9.720 \times 10^{-4}$ & 1 & $9.720 \times 10^{-4}$ & 0.47 & 0.5037 & n.s. \\
\hline $\mathrm{X}_{4}$ & $7.651 \times 10^{-3}$ & 1 & $7.651 \times 10^{-3}$ & 3.71 & 0.0747 & n.s. \\
\hline $\mathrm{X}_{1} \mathrm{X}_{2}$ & $9.303 \times 10^{-4}$ & 1 & $9.303 \times 10^{-4}$ & 0.45 & 0.5129 & n.s. \\
\hline $\mathrm{X}_{1} \mathrm{X}_{3}$ & $9.312 \times 10^{-3}$ & 1 & $9.312 \times 10^{-3}$ & 4.51 & 0.0519 & n.s. \\
\hline $\mathrm{X}_{1} \mathrm{X}_{4}$ & $1.103 \times 10^{-4}$ & 1 & $1.103 \times 10^{-4}$ & 0.053 & 0.8205 & n.s. \\
\hline $\mathrm{X}_{2} \mathrm{X}_{3}$ & $3.610 \times 10^{-4}$ & 1 & $3.610 \times 10^{-4}$ & 0.17 & 0.6821 & n.s. \\
\hline $\mathrm{X}_{2} \mathrm{X}_{4}$ & $3.782 \times 10^{-3}$ & 1 & $3.782 \times 10^{-3}$ & 1.83 & 0.1972 & n.s. \\
\hline $\mathrm{X}_{3} \mathrm{X}_{4}$ & $1.482 \times 10^{-3}$ & 1 & $1.482 \times 10^{-3}$ & 0.72 & 0.4109 & n.s. \\
\hline $\mathrm{X}_{1}^{2}$ & 0.12 & 1 & 0.12 & 57.84 & $<0.0001$ & ${ }_{* *}^{110.0 .}$ \\
\hline $\mathrm{X}_{2}{ }^{2}$ & 0.12 & 1 & 0.12 & 58.59 & $<0.0001$ & $* *$ \\
\hline $\mathrm{X}_{3}^{2}$ & 0.098 & 1 & 0.098 & 47.38 & $<0.0001$ & ** \\
\hline $\begin{array}{l}\mathrm{A}_{3} \\
\mathrm{X}_{4}^{2}\end{array}$ & 0.11 & 1 & $\begin{array}{l}0.070 \\
0.11\end{array}$ & 51.83 & $<0.0001$ & ** \\
\hline Residual & 0.029 & 14 & $2.063 \times 10^{-3}$ & & & \\
\hline Lack of fit & 0.026 & 10 & $2.611 \times 10^{-3}$ & 3.76 & 0.1070 & n.s. \\
\hline Pure error & $2.781 \times 10^{-3}$ & 4 & $6.952 \times 10^{-4}$ & & & \\
\hline Cor total & 0.34 & 28 & & & & \\
\hline $\mathrm{R}^{2}$ & 0.9156 & & & Adjusted $\mathrm{R}^{2}$ & 0.8312 & \\
\hline
\end{tabular}

${ }^{\mathrm{a}} \mathrm{X}_{1}$ : amount of cellulase (w/w, \%); $\mathrm{X}_{2}$ : Incubation time (h); $\mathrm{X}_{3}$ : Liquid-to-solid ratio (mL/g); $\mathrm{X}_{4}$ : Ethanol concentration (v/v, \%); Degree of freedom; ${ }^{\mathrm{c}}{ }^{*} p<0.05$ significant; ${ }^{* *} p<0.01$ highly significant; $n$.s. means not significant

Table 4: The influence of cellulase on TFCB release.

\begin{tabular}{llllllll}
\hline Method & $\mathrm{X}_{1}$ & $\mathrm{X}_{2}$ & $\mathrm{X}_{3}$ & $\mathrm{X}_{4}$ & Time $(\mathrm{h})$ & Temperature $\left({ }^{\circ} \mathrm{C}\right)$ & Yield $(\mathrm{w} / \mathrm{w}, \boldsymbol{\%})^{\mathrm{a}}$ \\
\hline HRE & - & 2 & $35: 1$ & 71 & 2 & 80 & $0.958 \pm 0.04$ \\
CAE & 0.4 & 2 & $35: 1$ & 71 & 2 & 80 & $1.284 \pm 0.01^{* *}$ \\
\hline
\end{tabular}

$\mathrm{X}_{1}$ : Amount of cellulase (w/w, \%); $\mathrm{X}_{2}$ : Incubation time $(\mathrm{h}) ; \mathrm{X}_{3}$ : Liquid-to-solid ratio $(\mathrm{mL} / \mathrm{g}) ; \mathrm{X}_{4}$ : ethanol concentration (v/v, \%); ${ }^{\mathrm{a}} \mathrm{TFCB}$ extraction yields were expressed as means $\pm \mathrm{SD} ;{ }^{* *} p<0.01$ highly significant versus HRE

Table 5: The $\mathrm{IC}_{50}$ values and reducing power of TFCB and VC. $\mathrm{IC}_{50}(\mu \mathrm{g} / \mathrm{mL})$

\begin{tabular}{lllll} 
Sample & DPPH radical & Hydroxyl radical & Superoxide anion & Reducing power $(\mu \mathrm{g} / \mathrm{mL})^{\mathrm{a}}$ \\
\hline TFCB & $34.02 \pm 0.52^{* *}$ & $200.55 \pm 6.43^{* *}$ & $17.18 \pm 0.97$ & $10.39 \pm 0.21^{* *}$ \\
VC & $5.82 \pm 0.07$ & $47.36 \pm 1.20$ & $15.78 \pm 0.058$ & $7.87 \pm 0.017$ \\
\hline
\end{tabular}

${ }^{a}$ The corresponding concentrations of TFCB and VC, when $\mathrm{A}_{700 \mathrm{~nm}}=0.2$; data was expressed as the mean \pm SD $(\mathrm{n}=3)$; symbol indicates statistically significant differences, ${ }^{* *} p<0.01$ highly significant versus VC. 

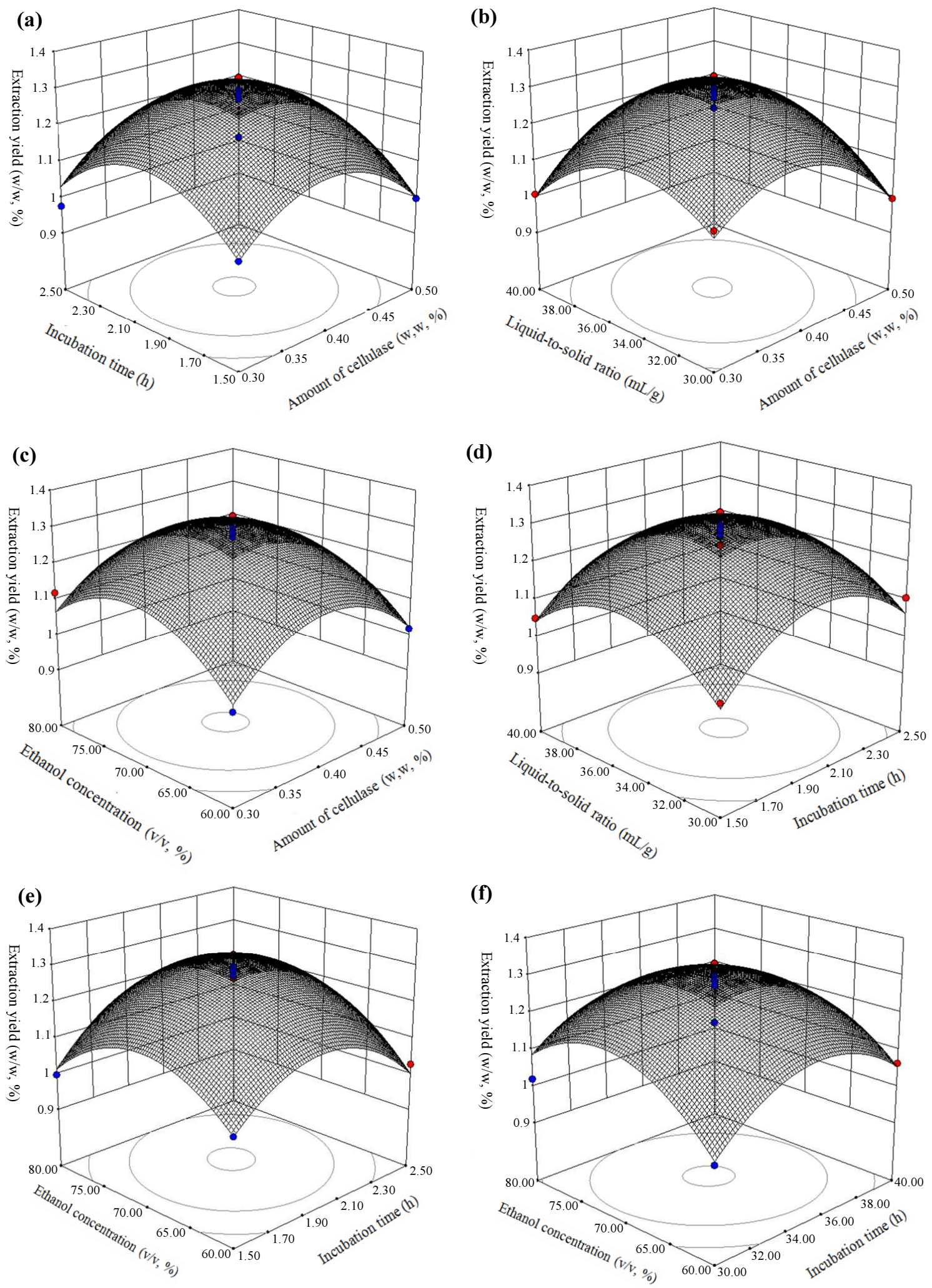

Fig. 3: Response surface plots (3-D) showing the effects of variables on TFCB extraction yield: (a) at varying amount of cellulase $\left(\mathrm{X}_{1}\right)$ and incubation time $\left(\mathrm{X}_{2}\right)$; (b) at varying amount of cellulase $\left(\mathrm{X}_{1}\right)$ and liquid-to-solid ratio $\left(\mathrm{X}_{3}\right)$; (c) at varying amount of cellulase $\left(\mathrm{X}_{1}\right)$ and ethanol concentration $\left(\mathrm{X}_{4}\right) ;(\mathrm{d})$ at varying incubation time $\left(\mathrm{X}_{2}\right)$ and liquid-to-solid ratio $\left(\mathrm{X}_{3}\right)$; (e) at varying incubation time $\left(\mathrm{X}_{2}\right)$ and ethanol concentration $\left(\mathrm{X}_{4}\right)$; (f) at varying liquid-to-solid ratio $\left(\mathrm{X}_{3}\right)$ and ethanol concentration $\left(\mathrm{X}_{4}\right)$ 

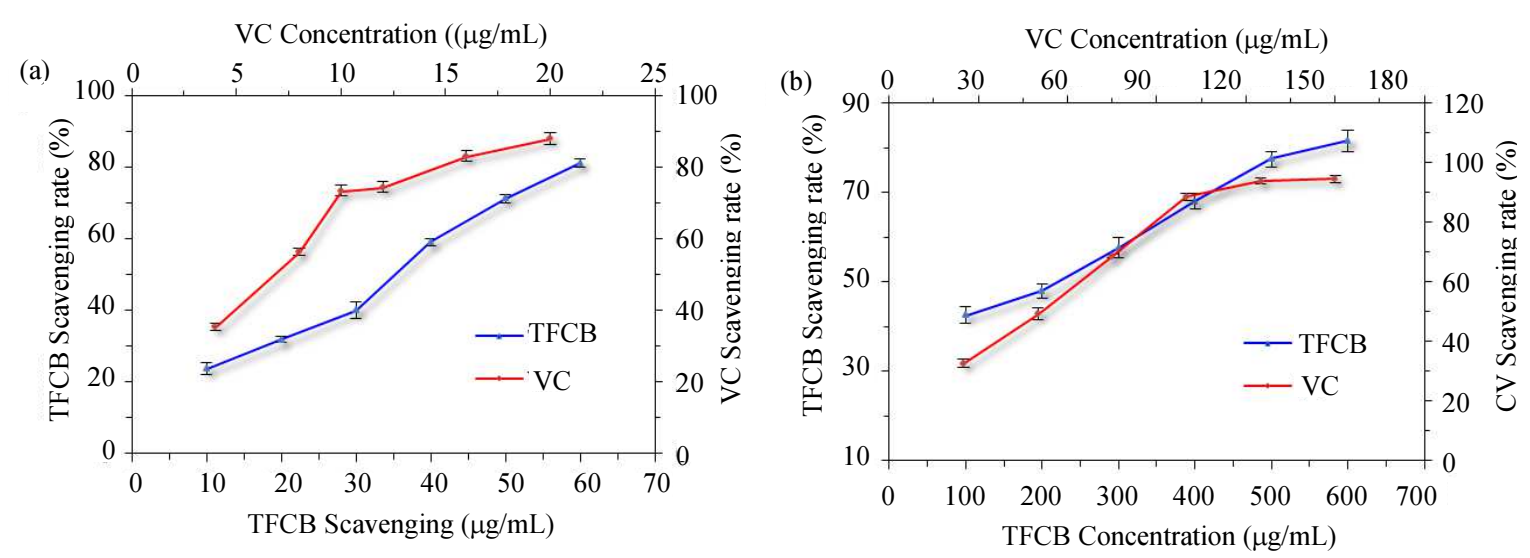

VC Concentration $((\mu \mathrm{g} / \mathrm{mL})$
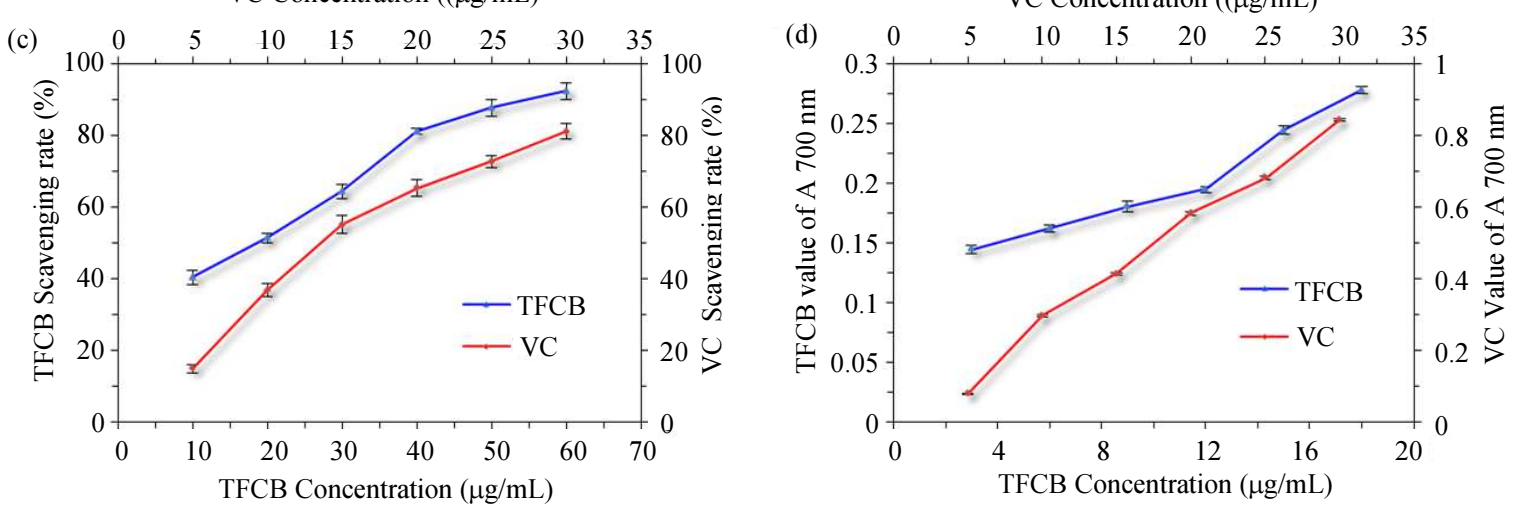

Fig. 4: The in vitro antioxidant evaluation of TFCB using VC as positive control. (a) DPPH radical-scavenging capacity; (b) Hydroxyl radical-scavenging capacity; (c) superoxide anion radical-scavenging capacity; (d) reducing power. Data was expressed as the means $\pm \mathrm{SD}(\mathrm{n}=3)$

\section{In vitro Antibacterial Activity of TFCB}

The Minimum Inhibitory Concentration (MIC) of TFCB against five bacterial species were summarized in Table 6. In the concentration range $0.50 \mu \mathrm{g} / \mathrm{mL}$ to 50.0 $\mu \mathrm{g} / \mathrm{mL}$, the MIC values of TFCB against $S$. aureus, $B$. pumilus, B. subtilis and $S$. typhimurium were 18.0, 6.48, 10.8 and $50.0 \mu \mathrm{g} / \mathrm{mL}$, respectively. These results indicated that TFCB may exhibit more inhibitory effects on Grampositive bacteria than Gram-negative ones, which deserved to be further investigated in the near future.

\section{In vivo Antioxidant Activity of TFCB}

In order to confirm the in vivo antioxidant activity of TFCB, an ethanol-induced oxidative stress mouse model was adopted using $\mathrm{VC}$ as positive control and four antioxidant-related biomarkers including Malondialdehyde (MDA), Total Superoxide Dismutase (T-SOD), Glutathione (GSH) and Protein Carbonyls (PCO) were selected.

\section{Effects of TFCB on MDA}

MDA is one of the most common final metabolic products of lipid peroxidation, its quantity is usually in proportion to the oxidative stress-related damages (Esterbauer et al., 1991). As shown in Fig. 5a, MDA content decreased in a dose-dependent manner $(p<0.05)$, when dose was $200 \mathrm{mg} / \mathrm{kg}$, MDA content reached the lowest level of $7.22 \pm 1.92 \mathrm{mmol} / \mathrm{L}, 1.8$-fold lower than that in $\mathrm{MC}$ and 1.4-fold lower than that in PC. Statistical analysis revealed that significant differences $(p<0.01)$ between $\mathrm{NC}$ and MC were found; there were significant differences $(p<0.01)$ between $\mathrm{MC}$ and all TFCB-treated groups; when compared with PC, significant differences $(p<0.01)$ were observed in $200 \mathrm{mg} / \mathrm{kg}$ of TFCB-treated group.

\section{Effects of TFCB on T-SOD}

SOD is a kind of antioxidase that possesses scavenging capacities against superoxide by changing the high reactive superoxide to the low hydrogen peroxide via dismutation reaction. Three isozymes of SOD, namely SOD- 1 , SOD-2 and SOD-3 have been reported, they show different biological localizations and enzyme characteristics, but catalyze the same reaction (Hu et al., 2007). As shown in Fig. 5b, when compared with NC, T-SOD activities in MC were reduced significantly $(p<0.01)$. There were statistically 
significant differences $(p<0.05, p<0.01)$ between MC and all TFCB-treated groups. Oral administration of TFCB can enhance T-SOD activities in a dose- dependent manner $(p<0.05)$, significant differences $(p<0.05)$ were found in $200 \mathrm{mg} / \mathrm{kg}$ of TFCB-treated group compared with PC.

Table 6: The Minimum inhibitory concentration of TFCB

\begin{tabular}{|c|c|c|c|c|c|}
\hline TFCB $(\mu \mathrm{g} / \mathrm{mL})$ & S. aureus & B. pumilus & B. subtilis & E. coli & S. typhimurium \\
\hline 0.50 & - & - & - & - & - \\
\hline 0.84 & - & - & - & - & - \\
\hline 1.40 & - & - & - & - & - \\
\hline 2.33 & - & - & - & - & - \\
\hline 3.89 & - & - & - & - & - \\
\hline 6.48 & - & + & - & - & - \\
\hline 10.8 & - & ++ & + & - & - \\
\hline 18.0 & + & +++ & ++ & - & - \\
\hline 30.0 & ++ & ++++ & ++ & - & - \\
\hline 50.0 & +++ & +++++ & +++ & - & + \\
\hline
\end{tabular}

(a)

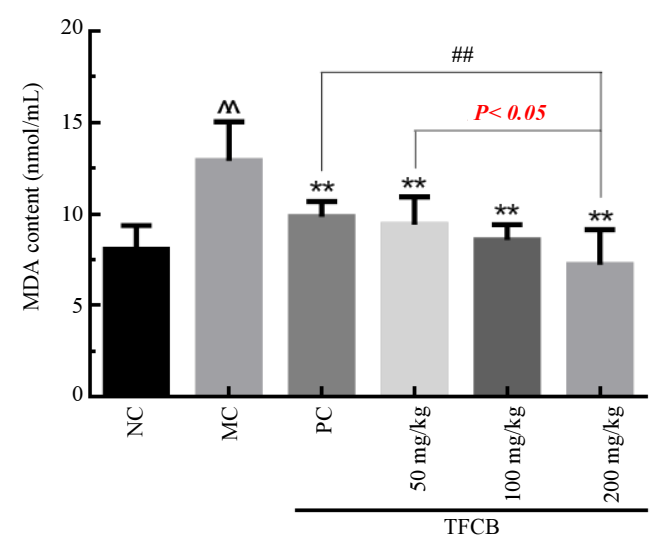

(c)

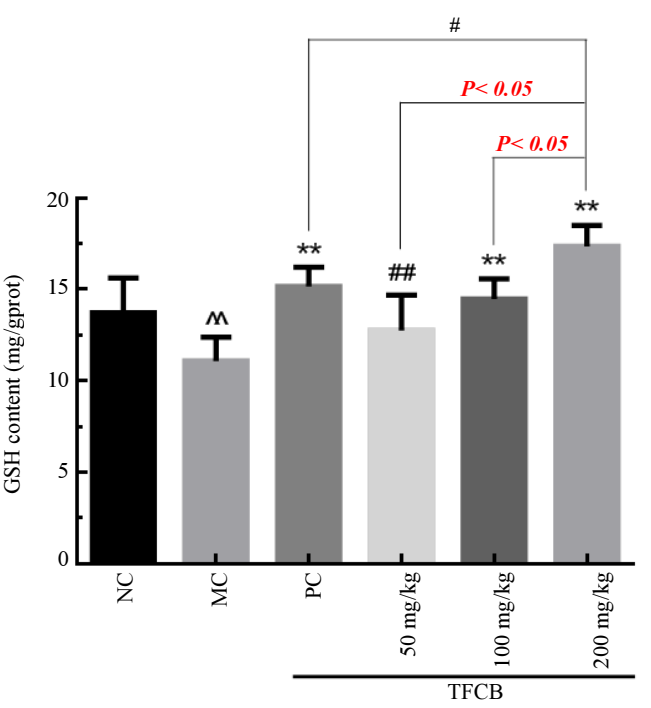

(b)
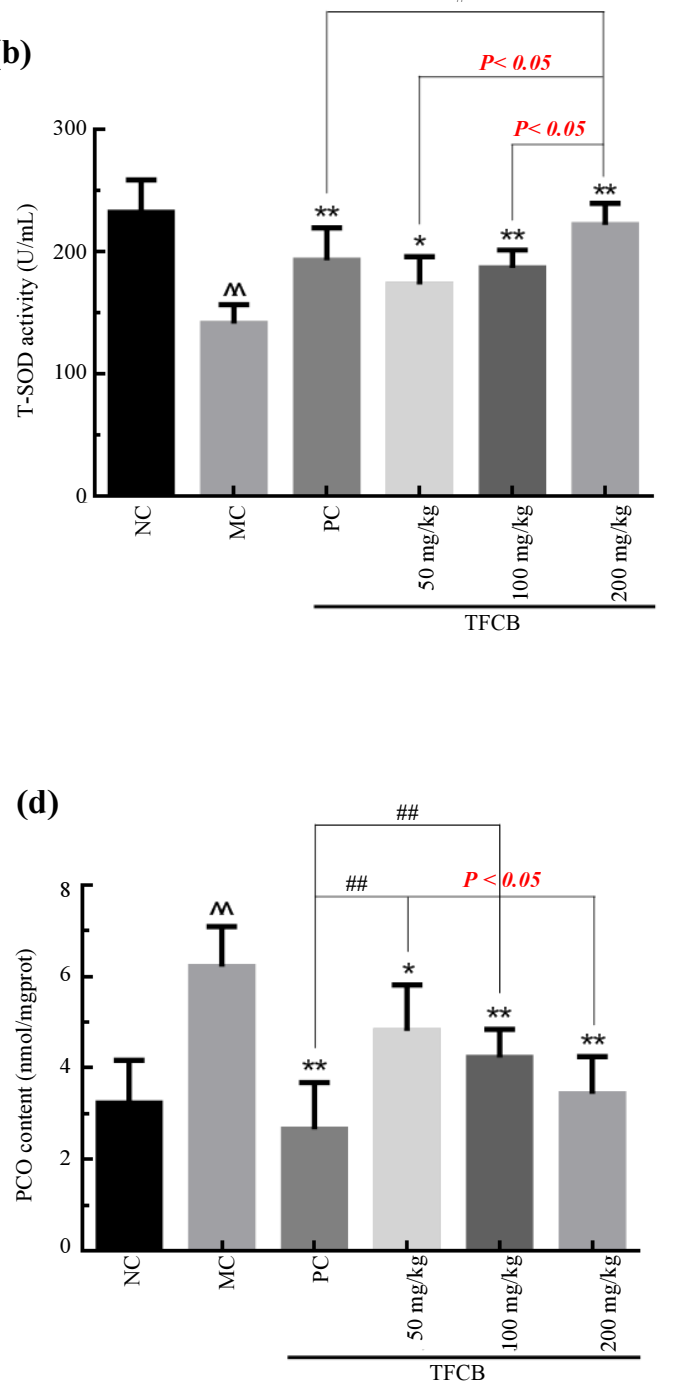

Fig. 5: Effects of TFCB on (a) MDA, (b) T-SOD, (c) GSH and (d) PCO. Data denoted were means + SD (n = 10). Different symbols indicate statistically significant differences, ${ }^{\wedge} p<0.01$ as compared with $\mathrm{NC}$ group; ${ }^{*} p<0.05,{ }^{* *} p<0.01$ as compared with MC group; ${ }^{\#} p<0.05,{ }^{\#} p<0.01$ as compared with PC group. NC: Normal Control; MC: Model Control; PC: Positive Control (VC in a dose of $200 \mathrm{mg} / \mathrm{kg}$ ) 


\section{Effects of TFCB on GSH}

GSH is one of the most important antioxidants that widely participate in the detoxification of xenobiotic substances, it is a tri-peptide condensed by glutamic acid, cysteine and glycine, thus owing to the presence of thiol group, GSH can directly react with free radicals (Bray and Taylor, 1993). As shown in Fig. 5c, significant differences $(p<0.01)$ in GSH content were noted between $\mathrm{NC}$ and MC. When compared with $\mathrm{MC}$, there were significant differences $(p<0.01)$ in PC and two TFCB-treated groups (100 and $200 \mathrm{mg} / \mathrm{kg})$. GSH content was raised in a dose-dependent manner $(p<0.05)$, when compared with PC, GSH content in 50 $\mathrm{mg} / \mathrm{kg}$ of TFCB-treated group was significantly lower $(p<0.01)$, however, when dose was elevated to 200 $\mathrm{mg} / \mathrm{kg}$, GSH content was significantly higher $(p<0.05)$ than that in PC.

\section{Effects of TFCB on PCO}

PCO is an irreversible form of protein oxidation, which is more stable than MDA and usually forms earlier than other oxidative stress-related biochemical indicators (Weber et al., 2015). As shown in Fig. 5d, PCO content in NC was significantly lower $(p<0.01)$ than that in MC. Significant differences $(p<0.05, p<0.01)$ were found in PC and all TFCB-treated groups compared with MC. PCO content decreased in a dose-dependent manner $(p<0.05)$, but inferior to PC, PCO contents in 50 and $100 \mathrm{mg} / \mathrm{kg}$ of TFCB-treated groups were significantly higher $(p<0.01)$ than that in PC and PCO content in $200 \mathrm{mg} / \mathrm{kg}$ of TFCB-treated group was $3.44 \pm 0.82 \mathrm{nmol} / \mathrm{mgprot}$, which was still higher than that of PC (2.67 $\pm 1.02 \mathrm{nmol} / \mathrm{mgprot})$.

These results revealed that oral administration of TFCB can depress the oxidative stress induced by ethanol in mice and exerts more effects on MDA, TSOD and GSH than on PCO. The underlying mechanisms may involve in reducing MDA and PCO formation as well as increasing T-SOD activities and GSH biosynthesis. The in vivo antioxidant activity of TFCB was raised in a dose-dependent manner $(p<0.05)$, when dose was elevated to $200 \mathrm{mg} / \mathrm{kg}$, significant differences $(p<0.05, p<0.01)$ in MDA, T-SOD and GSH were observed compared with PC (VC in a dose of 200 $\mathrm{mg} / \mathrm{kg}$ ), which contradicted with the results of the in vitro evaluation of antioxidant activity, where TFCB showed weaker free radical-scavenging capacities and reducing power to ferric ion than those of $\mathrm{VC}$ in most cases (Fig. 4). These results were consistent with the general findings that several in vivo metabolites of flavonoids, especially flavonoid glycosides may equally contribute their antioxidant activities (Arora et al., 1998; Miyake et al., 2000; Lemmens et al., 2015). However, the exact mechanisms of the in vivo antioxidant activity of TFCB are still unclear.

\section{Conclusion}

In this study, RSM was applied to optimize the extraction conditions of CAE for TFCB by using BBD to obtain the optimal conditions as follows: Amount of cellulase, $0.4 \%(\mathrm{w} / \mathrm{w})$; incubation time, $2 \mathrm{~h}$; liquidto-solid ratio, 35: $1 \mathrm{~mL} / \mathrm{g}$; ethanol concentration, $71 \%$ $(\mathrm{v} / \mathrm{v})$. Under these conditions, the TFCB yield was $1.284 \pm 0.01 \%(\mathrm{w} / \mathrm{w})$, which was $25.39 \%$ higher than that of heat reflux extraction. In vitro, TFCB showed scavenging capacities on DPPH, hydroxyl and superoxide anion radicals as well as reducing power to ferric iron in different concentration ranges; exhibited inhibitory effects against the Gram positive bacteria (S. aureus, B. pumilus and B. subtilis), but little impact on the Gram negative ones ( $E$. coli and $S$. typhimurium). In vivo, TFCB exerted antioxidant activities via reducing MDA and $\mathrm{PCO}$ formation as well as increasing T-SOD activity and GSH biosynthesis in ethanol-induced oxidative stress mice model. The stronger in vivo antioxidant activity was contradicted with the results obtained from the in vitro antioxidant evaluation compared with $\mathrm{VC}$, suggesting that TFCB metabolites could also contribute to the antioxidant activities, which deserved to be further studied. In addition, the chemical compositions of TFCB will be equally needed further study to explore in the near future.

\section{Acknowledgement}

The authors express their gratitude to Mr Daojun WANG, the chief executive officer of Huangzhihua Pharmaceutical Co., Ltd., for his support.

\section{Funding Information}

This work is founded by the Scientific Research Foundation of Changshu Institute of Technology (KYZ2018067Q) and the Key Program of 2019 TeamGuided Graduation Thesis of Changshu Institute of Technology.

\section{Author's Contributions}

Yang Zhang and Zhaowei Yan: Conceived and designed the experiments.

Jing Lu: Performed the experiments of in vitro antioxidant and antibacterial evaluations.

Leijie Ben, Lixue Zheng, Pengfei $\mathrm{Xu}$ and Yingang Jia: Optimized the extraction process.

Zhenyu Cheng: Processed the data.

Zhaowei Yanb Carried out the antioxidant activities of TFCB in mice.

Yang Zhang: Wrote manuscript.

Zhaowei Yan: Revised the manuscript. 


\section{Ethics}

Authors declared no ethical issues that may arise after the publication of this manuscript.

\section{References}

Arora, A., M.G. Nair and G.M. Strasburg, 1998. Antioxidant activities of isoflavones and their biological metabolites in a liposomal system. Arch. Biochem. Biophys., 356: 133-141.

DOI: 10.1006/abbi.1998.0783

Barth, S., 2008. Genetic Improvement of Bioenergy Crops. In: Genetic Improvement of Corn for Lignocellulosic Feedstock Production, de Natalia, L. and G.C. James (Eds.), Springer, New York, ISBN-13: 9780387708058.

Bisi-Johnson, M.A., C.L. Obi, B.B. Samuel, J.N. Eloff and A.I. Okoh, 2017. Antibacterial activity of crude extracts of some South African medicinal plants against multidrug resistant etiological agents of diarrhoea. BMC Complement. Altern. Med., 17: 321-321. DOI: 10.1186/s12906-017-1802-4

Bray, T.M. and C.G. Taylor, 1993. Tissue glutathione, nutrition and oxidative stress. Can. J. Physiol. Pharmacol., 71: 746-751. DOI: 10.1139/y93-111

Chen, S., X.H. Xing, J.J. Huang and M.S. Xu, 2011. Enzyme-assisted extraction of flavonoids from Ginkgo biloba leaves: Improvement effect of flavonol transglycosylation catalyzed by Penicillium decumbens cellulase. Enzyme Microb. Technol., 48: 100-105. DOI: 10.1016/j.enzmictec.2010.09.017

de Camargo, A.C., M.A.B Regitano-d'Arce, G.B. Rasera, S.G. Canniatti-Brazaca and L. do Prado-Silva et al., 2017. Phenolic acids and flavonoids of peanut byproducts: Antioxidant capacity and antimicrobial effects. Food Chem., 237: 538-544.

DOI: 10.1016/j.foodchem.2017.05.046

El-Beshbishy, H.A., A.M. Mohamadin and A.B. AbdelNaim, 2009. In vitro, evaluation of the antioxidant activities of grape seed (Vitis vinifera) extract, blackseed (Nigella sativa) extract and curcumin. J. Taibah Univ. Med. Sci., 4: 23-35. DOI: $10.1016 / \mathrm{S} 1658-3612(09) 70090-3$

Erasto, P., G. Bojase-Moleta and R.R. Majinda, 2004. Antimicrobial and antioxidant flavonoids from the root wood of Bolusanthus speciosus. Phytochemistry, 65: 875-880. DOI: 10.1016/j.phytochem.2004.02.011

Esterbauer, H., R.J. Schaur and H. Zollner, 1991. Chemistry and biochemistry of 4-hydroxynonenal, malonaldehyde and related aldehydes. Free Radic. Biol. Med., 11: 81-128.

DOI: $10.1016 / 0891-5849(91) 90192-6$
Fu, Y.J., W. Liu, Y.G. Zu, M.H. Tong and S.M. Li et al., 2008. Enzyme assisted extraction of luteolin and apigenin from pigeonpea [Cajanuscajan (L.) Millsp.] leaves. Food Chem., 111: 508-512. DOI: 10.1016/j.foodchem.2008.04.003

Gao, W., S.U. Lee, J. Li and J.W. Lee, 2016. Development of improved process with treatment of cellulase for isolation of ampelopsin from dried fruits of Ampelopsis grossedentata. BioResources, 11: 2712-2722. DOI: 10.15376/biores.11.1.2712-2722

Hasanudin, K., P. Hashim and S. Mustafa, 2012. Corn silk (Stigma maydis) in healthcare: A phytochemical and pharmacological review. Molecules, 17: 9697-9715. DOI: 10.3390/molecules 17089697

Hong, J., J.Y. Hu, J.H. Liu, Z. Zhou and A.F. Zhao, 2014. In vitro antioxidant and antimicrobial activities of flavonoids from Panax notoginseng flowers. Nat. Prod. Res., 28: 1260-1266.

DOI: $10.1080 / 14786419.2014 .900768$

Hu, D., E. Klann and E. Thiels, 2007. Superoxide dismutase and hippocampal function: Age and isozyme matter. Antioxid. Redox. Signal., 9: 201-210. DOI: 10.1089/ars.2007.9.201

Huang, D., X. Zhou, J. Si, X. Gong and S. Wang, 2016. Studies on cellulase-ultrasonic assisted extraction technology for flavonoids from Illicium verum residues. Chem. Cent. J., 10: 56.

DOI: $10.1186 / \mathrm{s} 13065-016-0202-\mathrm{z}$

Jing, S., S. Wang, Q. Li, L. Zheng and L. Yue et al., 2016. Dynamic high pressure microfluidizationassisted extraction and bioactivities of Cyperus esculentus (C. esculentus L.) leaves flavonoids. Food Chem., 192: 319-327. DOI: 10.1016/j.foodchem.2015.06.097

Ke, L.Q. and H.Y. Chen, 2016. Enzymatic-assisted microwave extraction of total flavonoids from bud of Chrysanthemum indicum L. and evaluation of biological activities. Int. J. Food Eng., 12: 607-613. DOI: 10.1515/ijfe-2015-0037

Khorasani, E.A, T.R Mat, S. Mohajer and B. Banisalam, 2015. Antioxidant activity and total phenolic and flavonoid content of various solvent extracts from in vivo and in vitro grown Trifolium pratense L. (Red Clover). Biomed. Res. Int., 2015: 643285-643285. DOI: $10.1155 / 2015 / 643285$

Lee, H.C. and Y.H. Wei, 2001. Mitochondrial alterations, cellular response to oxidative stress and defective degradation of proteins in aging. Biogerontology, 2: 231-244. DOI: $10.1023 / \mathrm{A}: 1013270512172$

Lemmens, K.J., P.M. Herst, B.A. Housmans, M. Moalin and W.J. Vijgh et al., 2015. The contribution of the major metabolite 4'-O-methylmonoHER to the antioxidant activity of the flavonoid monoHER. Chem. Biol. Interact., 239: 146-152. DOI: 10.1016/j.cbi.2015.07.004 
Liu, H., M. Zhang, Y. Guo and H. Qiu, 2016. Solidphase extraction of flavonoids in honey samples using carbamate-embedded triacontyl-modified silica sorbent. Food Chem., 204: 56-61. DOI: 10.1016/j.foodchem.2016.02.102

Liu, H., Y. Mou, J. Zhao, J. Wang and L. Zhou et al., 2010. Flavonoids from Halostachys caspica and their antimicrobial and antioxidant activities. Molecules, 15: 7933-7945.

DOI: 10.3390/molecules 15117933

Liu, W., Y.J. Fu, Y.G. Zu, M.H. Tong and N. Wu et al., 2009. Supercritical carbon dioxide extraction of seed oil from Opuntia dillenii Haw. and its antioxidant activity. Food Chem., 114: 334-339. DOI: 10.1016/j.foodchem.2008.09.049

Luo, T., X. Tian, C. Yang, W. Luo and Y. Nie et al., 2017. Polyethylenimine-functionalized corn bract, an agricultural waste material, for efficient removal and recovery of $\mathrm{Cr}$ (VI) from aqueous solution. J. Agric. Food Chem., 65: 7153-7158. DOI: $10.1021 /$ acs.jafc.7b02699

Mao, X.B., C.S. Gu, D.W. Chen, B. Yu and J. He, 2017. Oxidative stress-induced diseases and tea polyphenols. Oncotarget, 8: 81649-81661. DOI: $10.18632 /$ oncotarget.20887

Martinez-Useros, J., W. Li, M. Cabeza-Morales and J. Garcia-Foncillas, 2017. Oxidative stress: A new target for pancreatic cancer prognosis and treatment. J. Clin. Med., 6: 29-29. DOI: 10.3390/jcm6030029

Miyake, Y., K. Shimoi, S. Kumazawa, K. Yamamoto and N. Kinae et al., 2000. Identification and antioxidant activity of flavonoid metabolites in plasma and urine of eriocitrin-treated rats. J. Agric. Food Chem., 48: 3217-3224. DOI: 10.1021/jf990994g

NWE, 2018. Maize. New World Encyclopedia. http://www.newworldencyclopedia.org/entry/Maize

Peng, K.Z., S.Y. Zhang and H.L. Zhou, 2016. Toxicological evaluation of the flavonoid-rich extract from Maydis stigma: Subchronic toxicity and genotoxicity studies in mice. J. Ethnopharmacol., 192: 161-169. DOI: 10.1016/j.jep.2016.07.012

Peng, K.Z., X. Yang, H.L. Zhou and S.X. Pan, 2015. Safety evaluation, in vitro and in vivo antioxidant activity of the flavonoid-rich extract from Maydis stigma. Molecules, 20: 22102-22112.

DOI: $10.3390 /$ molecules201219835

Sarian, M.N., Q.U. Ahmed, S.Z. Mat So'ad, A.M. Alhassan and S. Murugesu et al., 2017. Antioxidant and antidiabetic effects of flavonoids: A structureactivity relationship based study. Biomed. Res. Int., 2017: 8386065-8386065.

DOI: $10.1155 / 2017 / 8386065$
Szuroczki, D., J. Koprivnikar and R.L. Baker, 2016. Dietary antioxidants enhance immunocompetence in larval amphibians. Comp. Biochem. Physiol. A Mol. Integr. Physiol., 201: 182-188.

DOI: 10.1016/j.cbpa.2016.07.014

Vaquero, M.J.R., L.R.T. Serravalle, M.C.M. de Nadra and A.M.S. de Saad, 2010. Antioxidant capacity and antibacterial activity of phenolic compounds from Argentinean herbs infusions. Food Control, 21: 779-785.

DOI: 10.1016/j.foodcont.2009.10.017

Wang, L., Y. Wu, Y. Liu and Z. Wu, 2017. Complex enzyme-assisted extraction releases antioxidative phenolic compositions from guava leaves. Molecules, 22: 1648.

DOI: 10.3390/molecules22101648

Wang, Y., Y. Zu, J. Long, Y. Fu and S. Li et al., 2011. Enzymatic water extraction of taxifolin from wood sawdust of Larix gmelini (Rupr.) Rupr. and evaluation of its antioxidant activity. Food Chem., 126: 1178-1185.

DOI: 10.1016/j.foodchem.2010.11.155

Weber, D., M.J. Davies and T. Grune, 2015. Determination of protein carbonyls in plasma, cell extracts, tissue homogenates, isolated proteins: Focus on sample preparation and derivatization conditions. Redox Biol., 5: 367-380.

DOI: 10.1016/j.redox.2015.06.005

Xiao, W., L. Han and B. Shi, 2008. Microwave-assisted extraction of flavonoids from Radix Astragali. Sep. Purif. Technol., 62: 614-618.

DOI: $10.1016 /$ j.seppur.2008.03.025

Yang, R.F., L.L. Geng, H.Q. Lu and X.D. Fan, 2017. Ultrasound-synergized electrostatic field extraction of total flavonoids from Hemerocallis citrina baroni. Ultrason. Sonochem., 34: 571-579. DOI: 10.1016/j.ultsonch.2016.06.037

Yang, Y.C., J. Li, Y.G. Zu, Y.J. Fu and M. Luo et al., 2010. Optimisation of microwave-assisted enzymatic extraction of corilagin and geraniin from Geranium sibiricum Linne and evaluation of antioxidant activity. Food Chem., 122: 373-380. DOI: 10.1016/j.foodchem.2010.02.061

Yu, J., Q. Lou., X. Zheng, Z. Cui and J. Fu, 2017. Sequential combination of microwave-and ultrasound-assisted extraction of total flavonoids from Osmanthus fragrans Lour. flowers. Molecules, 22: 2216. DOI: 10.3390/molecules22122216

Zakaryan, H., E. Arabyan, A. Oo and K. Zandi, 2017. Flavonoids: Promising natural compounds against viral infections. Arch. Virol., 162: 2539-2551.

DOI: $10.1007 / \mathrm{s} 00705-017-3417-y$ 
Zhang, G.W., M.M. Hu, L. He, P. Fu and L. Wang et al., 2013. Optimization of microwave-assisted enzymatic extraction of polyphenols from waste peanut shells and evaluation of its antioxidant and antibacterial activities in vitro. Food Bioprod. Process, 91: 158-168.

DOI: $10.1016 /$ j.fbp.2012.09.003
Zhao, H.P., Y. Zhang, Z. Liu, J.Y. Chen and S.Y. Zhang et al., 2017. Acute toxicity and anti-fatigue activity of polysaccharide-rich extract from corn silk. Biomed. Pharmacother, 90: 686-693. DOI: 10.1016/j.biopha.2017.04.045 